\title{
EHEPГETИKA
}

УДК 662.995:662.997

DOI https://doi.org/10.32838/2663-5941/2020.4/19

Беляновська О.A.

ДВНЗ «Український державний хіміко-технологічний університет»

Пустовой Г.М.

ДВНЗ «Український державний хіміко-технологічний університет»

Cyxa I.B.

ДВНЗ «Український державний хіміко-технологічний університет»

Скляренко О.I.

ДВНЗ «Український державний хіміко-технологічний університет»

Сухий М.П.

ДВНЗ «Український державний хіміко-технологічний університет»

Губинський М.В.

Національна металургійна академія України

Сухий К.М.

ДВНЗ «Український державний хіміко-технологічний університет»

\section{ЕКСПЛУАТАЦІЙНІ ХАРАКТЕРИСТИКИ АДСОРБЦЙНОГО ХОЛОДИЛЬНОГО МОДУЛЯ ПАРОВОЇ КОМПРЕСІЙНОЇ ХОЛОДИЛЬНОЇ УСТАНОВКИ}

Розглянуто заходи з утилізації низько-потенційної теплової енергії під час експлуатації парових компресійних холодильних установок. Запропонована схема парової компресійної холодильної установки з адсорбиійним холодильним модулем, який включає холодильну камеру, адсорбер, випарник та конденсатор. Холодильним агентом в адсорбиійному холодильному модулі запропоновано використовувати воду. Розроблена процедура розрахунку експлуатаиійних характеристик адсорбиійного холодильного модуля, яка включає визначення маси води, маси адсорбенту, холодопродуктивності та холодильного коефіиієнта. Оиінено холодопродуктивність та холодильний коефіцієнт адсорбиійного холодильного модуля в умовах експлуатації типової парокомпресійної холодильної установки. Проаналізовано основні фактори, які впливають на ефективність адсорбиійного холодильного модуля. Встановлено, що холодопродуктивність та холодильний коефіцієнт адсорбиійного холодильного модуля визначаються тепловим навантаженням на конденсатор, i отже, масою води, яка десорбується та випаровується. Оиінено холодильний коефіиієнт адсорбиійного холодильного модуля, який дорівнює 0,878. Розглянуто критерії підбору адсорбентів для адсорбційного модуля - температура регенеращії, яка визначається температурами в конденсаторі, та гранична адсорбиія, яка визначає масу адсорбенту та розміри адсорбера. Порівняно ефективність адсорбиійних холодильних модулів на основі силікоалюмофосфатів та композитних адсорбентів «силікагель - натрій ацетат». Показана перспективність використання композитів «силікагель - $\mathrm{CH}_{3} \mathrm{COONa».} \mathrm{Встановлено} \mathrm{оптимальний} \mathrm{склад} \mathrm{ком-}$ позиту, який відповідає мінімальним розмірам адсорбера, 80\% натрій ацетату та 20\% силікагелю. Показана перспективність використання адсорбиійного перетворення теплової енергії для утилізації низько-потенційної теплової енергії під час експлуатації парових компресійних холодильних установок.

Ключові слова: адсорбиійне перетворення теплової енергії, композитний адсорбент, парова компресійна холодильна установка, адсорбиія, адсорбиійна ємність. 
Постановка проблеми. Для охолодження та зберігання сільськогосподарської продукції велике поширення отримали парові компресійні холодильні установки, в яких холодильним агентом $є$ рідини з низькими температурами кипіння. Практичне використання отримали переважно різні фтор-хлор-бром-похідні метану та етану, а також пропану та бутану (так звані хладони, або фреони) [1, с. 991; 2, с. 834]. Подібні системи включають випаровувач, де відбувається відведення теплоти від охолоджуваного середовища, компресор, який стискає пари холодоагента, конденсатор, в якому відбуваються охолодження холодоагента та відведення теплоти від холодоагента до навколишнього середовища, та дросель $[1$, c. 196]. Подібні системи є інтенсивними споживачами електричної енергії, особливо в літній період. Крім того, під час їх експлуатації доволі значна кількість теплоти викидається до навколишнього середовища, що призводить до теплового забруднення.

Це стимулює розробку заходів для утилізації низько-потенційної теплової енергії.

Аналіз останніх досліджень та публікацій. Перспективним рішенням $є$ адсорбційне перетворення теплової енергії, зокрема, адсорбційні холодильні установки. Основними елементами їх конструкції $є$ сонячний колектор, адсорбер, конденсатор та випаровувач, який встановлено біля холодильної камери [3, с. 2]. Зазвичай адсорбційна холодильна установка працює в дві стадії: адсорбція та випаровування холодильного агента, яка сприяє зниженню температури в холодильній камері, та регенерація адсорбенту, тобто десорбція холодильного агента та його конденсація.

Одним 3 перспективних холодоагентів завдяки екологічній безпеці та нетоксичності $є$ вода. Як адсорбенти пропонувались різні типи силікагелів $[3$, с. $3 ; 4$, с. $8 ; 5$, с. 86$]$, цеолітів $[6$, с. 520 ; 7 , с. 1120], металоорганічних координаційних полімерів MOF [8, с. 3] та композитних матеріалів типу «сіль у поринній матриці» $[9$, с. $1 ; 10$, с. 100].

Вочевидь, ключовим фактором, який впливає на конструктивні характеристики та ефективність адсорбційної холодильної установки, $\epsilon$ властивості адсорбенту.

Доцільно розглянути можливість впровадження адсорбційного модуля до парової компресійної холодильної установки.

Постановка завдання дослідження. Метою дослідження $\epsilon$ встановлення експлуатаційних характеристик адсорбційного холодильного модуля парової компресійної холодильної уста- новки. Для досягнення зазначеної мети поставлено такі завдання:

- розробити процедуру розрахунку конструктивних характеристик модуля;

- виявити основні критерії підбору адсорбенту;

- оцінити ефективність адсорбційного холодильного модуля.

Виклад основного матеріалу дослідження. Схема запропонованої установки представлена на рис. 1. Така система включає два контури. Перший, який відповідає традиційній парокомпресійній холодильній установці, включає компресор 1, конденсатор 2, дросель 3 та випаровувач 4. Як холодильний агент у першому контурі пропонується використовувати будь-який традиційний холодоагент, наприклад, R407C. Другий контур включає адсорбер 5, заповнений адсорбентом, в якому розміщено теплообмінник 6 , додаткову холодильну камеру 7, конденсатор 8 та випаровувач 9. У другому контурі як холодоагент пропонується використовувати воду.

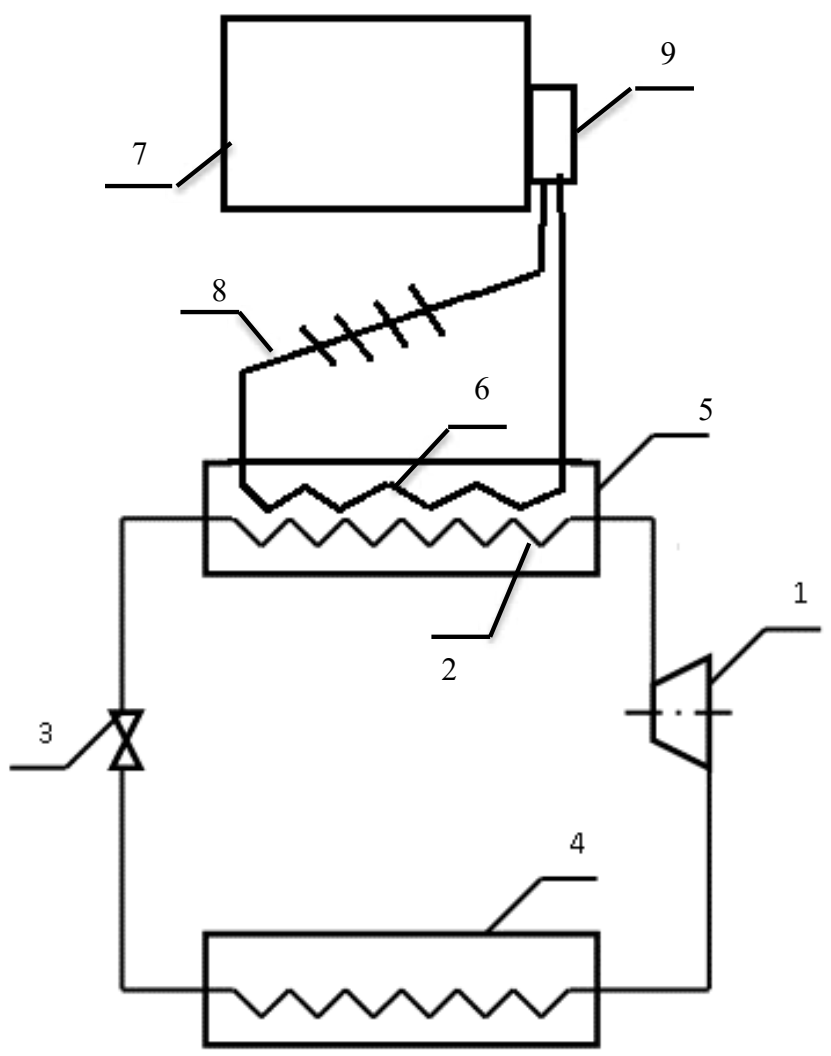

Рис. 1. Схема парової компресійної холодильної установки з адсорбційним модулем

На відміну від традиційних установок, цикл теплоти від конденсатора 2 пропонується використовувати для підігріву адсорбенту та його регенерації. 
Адсорбційний холодильний модуль працює відповідно до термодинамічного циклу, який наведено на рис. 2.

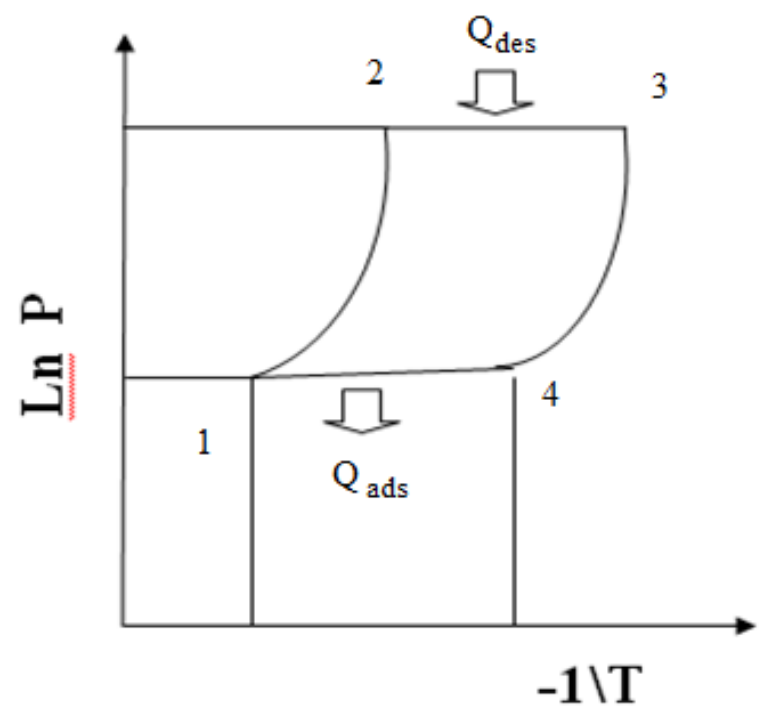

Рис. 2. Робочий цикл адсорбційного холодильного модуля [11]

Регенерацію адсорбенту, тобто десорбцію та конденсацію води, зображують лінії $1-2-3$, а отримання холоду, тобто адсорбцію та випаровування води, - лінії $3-4-1$.

Експлуатація адсорбційного холодильного модуля здійснюється в два етапи - отримання холоду та регенерації адсорбенту. На першому етапі пари води дифундують через конденсатор 8 до адсорбера 5. Адсорбція води адсорбційним матеріалом сприяє її випаровуванню у випарнику, що створює холодильний ефект у додатковій холодильній камері 7. На другому етапі нагрівають адсорбент, використовуючи теплоту конденсації. Вода десорбується та збирається в конденсаторі 8, далі зливається у випарник 9 і починається процес отримання холоду.

Вочевидь, ключовим фактором, який визначає ефективність роботи адсорбційного модуля, $\epsilon$ перш за все властивості адсорбенту, зокрема його адсорбційна ємність та температура регенерації. Водночас вибір адсорбентів за цими критеріями обмежено експлуатаційними характеристиками парових компресійних холодильних установок.

Так, відповідно до результатів розрахунку за традиційною методикою під час експлуатації типової парокомпресійної холодильної установки холодопродуктивністю 322,7 кВт теплове навантаження на повітряний конденсатор становить
434,18 кВт за температури конденсації на рівні $40{ }^{\circ} \mathrm{C}$. Іншим технічним рішенням $€$ використання як конденсатора зануреного кожухотрубчастого теплообмінника, в якому холодоагент буде передавати теплоту перегріву та конденсації теплоносію, тобто воді, яка буде циркулювати в системі теплопостачання. При цьому холодильний коефіцієнт становить 3,56. За умови температури холодоагента в конденсаторі на рівні $70^{\circ} \mathrm{C}$ теплове навантаження на конденсатор становитиме 484,7 кВт. Холодильний коефіцієнт такої установки знижується до 2,8.

Далі проведено розрахунок адсорбційного модуля, маси води та холодопродуктивності додаткової холодильної камери. Розрахунок проводився відповідно до методики, яка є зворотною до розробленої в [11, с. 39].

На першій стадії пропонується проводити розрахунок маси води:

$$
M_{\mathrm{H}_{2} \mathrm{O}}=\frac{Q_{1} \cdot \tau}{\Delta H_{\text {des }}}
$$

де $M_{\mathrm{H}_{2} \mathrm{O}}$ - маса води, кг; $Q_{1}$ - теплове навантаження на конденсатор, кВт, $\tau$ - тривалість циклу, c, $\Delta H_{\text {des }}$ - теплота десорбції, кДж/кг.

Далі проводиться розрахунок маси адсорбенту як відношення маси води до граничної адсорбції:

$$
M_{a d s}=\frac{M_{\mathrm{H}_{2} \mathrm{O}}}{A_{\max }}
$$

де $M_{a d s}$ - маса адсорбенту, кг; $A_{\text {мax }}$ - гранична адсорбція, кг/кг; $M_{\mathrm{H}_{2} \mathrm{O}}-$ маса води, кг.

Далі проводиться розрахунок кількості теплоти, яку відведено від холодильної камери:

$$
Q_{2}^{\prime}=\left(M_{H_{2} O} \cdot \Delta H_{e v}\right) / \tau
$$

де $Q_{2}^{\prime}$ - кількість теплоти, яку відведено від додаткової холодильної камери, кВт; $M_{\mathrm{H}_{2} \mathrm{O}}$ - маса води, кг; $\Delta H_{e v}$ - питома теплота випаровування, кДж/кг; $\tau$ - тривалість циклу, с.

Холодильний коефіцієнт адсорбційного холодильного модуля пропонується визначати як відношення кількості теплоти, яку відведено від додаткової холодильної камери, до теплового навантаження на конденсатор.

Враховуючи температуру в конденсаторі, доцільно використати адсорбенти з температурою регенерації близько $60^{\circ} \mathrm{C}$. Цим вимогам відповідають силікоалюмофосфати [12, с. 87] та композитні адсорбенти «силікагель - натрій ацетат» $[13$, c. 82$]$.

Результати розрахунків наведені в таблиці 1. 
Таблиця 1

Експлуатаційні характеристики адсорбційного холодильного модуля

\begin{tabular}{|l|c|c|c|c|c|}
\hline \multicolumn{1}{|c|}{ Адсорбент } & $M_{H_{2} O}$, кг & $A_{\max }$, кг & $M_{a d s}$, кг & $Q_{2}^{\prime}$ & $\begin{array}{c}\text { Холодильний коефіцієнт } \\
\text { адсорбційного } \\
\text { холодильного модуля, } \varepsilon\end{array}$ \\
\hline Силікоалюмофосфат [12] & 306,13 & 0,250 & 1224,51 & 425,35 & 0,878 \\
\hline $\begin{array}{l}\text { Композит «Силікагель } \\
(20 \%) \text { - натрій ацетат } \\
(80 \%) »[14]\end{array}$ & 306,13 & 0,756 & 404,93 & 425,35 & 0,878 \\
\hline $\begin{array}{l}\text { Композит «Силікагель } \\
(40 \%)-\text { натрій ацетат } \\
(60 \%) »[14]\end{array}$ & 306,13 & 0,596 & 513,63 & 425,35 & 0,878 \\
\hline $\begin{array}{l}\text { Композит «Силікагель } \\
(60 \%)-\text { натрій ацетат } \\
(40 \%) »[14]\end{array}$ & 306,13 & 0,462 & 662,61 & 425,35 & 0,878 \\
\hline $\begin{array}{l}\text { Композит «Силікагель } \\
(80 \%)-\text { натрій ацетат } \\
(20 \%) »[14]\end{array}$ & 306,13 & 0,33 & 927,66 & 425,35 & 0,878 \\
\hline
\end{tabular}

Тепловому навантаженню на конденсатор 484,7 кВт за умови тривалості адсорбційного циклу 1 год. відповідає маса води 306,13 кг. Холодопродуктивність та холодильний коефіцієнт адсорбційного холодильного модуля для силікоалюмофосфатів та композитів «силікагель - натрій ацетат» залишаються практично ідентичними, оскільки вони визначаються перш за все тепловим навантаженням на конденсатор, що визначає масу води, яка випаровується. Але маса адсорбенту визначається, вочевидь, граничною адсорбцією.

Найменша гранична адсорбція та максимальна маса адсорбенту відповідають адсорбційному модулю на основі силікоалюмофосфату, який $€$ найменш ефективним.

Дещо менша маса адсорбенту, яка необхідна для поглинання заданої кількості води, встановлена для композиту, який містить $80 \%$ силікагелю та $20 \%$ натрій ацетату. Зростання вмісту солі, яка утворює кристалогідрат, тобто натрій ацетату, сприяє підвищенню граничної адсорбції, отже, зменшенню маси адсорбенту. Найменша маса адсорбенту, а отже, об’єм адсорбційного модуля відповідає композиту, який містить $20 \%$ силікагелю та 80\% натрій ацетату, який доцільно використовувати як адсорбційний матеріал.
Висновки. Розглянуто процеси утилізації низько-потенційної теплової енергії під час експлуатації парових компресійних холодильних установок. Запропонована схема парової компресійної холодильної установки 3 адсорбційним холодильним модулем.

Оцінено холодопродуктивність адсорбційного холодильного модуля в умовах експлуатації типової парокомпресійної холодильної установки. Показано, що холодопродуктивність та холодильний коефіцієнт адсорбційного холодильного модуля визначаються тепловим навантаженням на конденсатор, отже, масою води, яка десорбується та випаровується.

Розглянуто критерії підбору адсорбентів для адсорбційного модуля - температура регенерації, яку визначають температури в конденсаторі, та гранична адсорбція, яка визначає масу адсорбенту та розміри адсорбера.

Оцінено ефективність адсорбційних холодильних модулів на основі силікоалюмофосфатів та композитних адсорбентів «силікагель - натрій ацетат». Підтверджено перспективність використання композитів «силікагель - $\mathrm{CH}_{3} \mathrm{COONa».}$ Встановлено оптимальний склад композиту, який містить $80 \%$ натрій ацетату та $20 \%$ силікагелю, що відповідає мінімальним розмірам адсорбера.

\section{Список літератури:}

1. Мааке В., Эккерт К.-Ю., Кошпен Ж.Л. Учебник по холодильной технике. Москва : Издательство Московского университета, 1998.1142 с.

2. Calm J.M. Comparative efficiencies and implications for greenhouse gas emissions of chiller refrigerants. International Journal of Refrigeration. 2006. Vol. 29. Pp. 833-841

3. Rouf R.A., Jahan N., Alam K.C.A., Sultan A.A., Saha B.B., Saha S.C. Improved cooling capacity of a solar heat driven adsorption chiller. Case Studies in Thermal Engineering. 2020. Vol. 17. Pp. 100-568.

4. Mohamed M. Younes, Ibrahim I. El-Sharkawy, A.E. Kabeel, Kutub Uddin, Takahiko Miyazaki, Bidyut Baran Saha. Characterization of silica gel-based composites for adsorption cooling applications. International 
Journal of Refrigeration. 2020. In Press. Journal Pre-Proof. DOI: https://doi.org/10.1016/j.ijrefrig.2020.04.002.

5. Wang D., Zhang J., Tian X., Liu D., Sumathy K. Progress in silica gel - water adsorption refrigeration technology. Renewable and Sustainable Energy Reviews. 2014, Vol. 30, Pp. 85-104.

6. Wang L.W., Wang R.Z., Oliveira R.G.A. Review on adsorption working pairs for refrigeration. Renewable and Sustainable Energy Reviews. 2009. Vol. 13. Pp. 518-534.

7. Kayal S., Baichuan S., Saha B.B. Adsorption characteristics of AQSOA zeolites and water for adsorption chillers. Int. J. Heat Mass Transf., 2016. Vol. 92. P. 1120-1127.

8. Palash M.L., Jahan I., Rupam T.H., Harish S., Saha B.B. Novel technique for improving the water adsorption isotherms of metal-organic frameworks for performance enhancement of adsorption driven chillers. Inorganica Chimica Acta. 2020. Vol. 501, Pp. 119-313.

9. Aprile M., Freni A., Toppi T., Motta M. Modelling and Performance Assessment of a Thermally-Driven Cascade Adsorption Cycle Suitable for Cooling Applications. Thermal Science and Engineering Progress. 2020. Journal Pre-proofs. DOI: https://doi.org/10.1016/j.tsep.2020.100602.

10. Belyanovskaya E., Pustovoy G., Sukhyy M.P., Sukhyy K.M., Lytovchenko R. Performance evaluation of adsorptive refrigerators based on composite adsorbents "silica gel - sodium sulphate" and "silica gel - sodium acetate”. Scientific Works. 2019. Vol. 83(2). Pp. 96-101.

11. Беляновская Е.А., Пустовой Г.Н., Сухой К.М., Коломиец Е.В., Сухой М.П. Адсорбционные холодильные установки на основе композитных адсорбентов «силикагель - сульфат натрия». Вісник Начіонального технічного університету «ХПI» Серія: Хімія, хімічна технологія та екологія. 2018. № 39(1315). C. $38-42$.

12. Freni A., Maggio G., Sapienza A., Frazzica A., Restuccia G., Vasta S. Comparative analysis of promising adsorbent/adsorbate pairs for adsorptive heat pumping, air conditioning and refrigeration. Applied Thermal Engineering. 2016. Vol. 104, Pp. 85-95.

13. Sukhyy K.M., Belyanovskaya E.A., Sukha I.V., Kolomiyets E.V., Gavrilko A.V., Sukhyy M.P. Solar Adsorptive Chiller based on Composite Sorbent "Silica Gel - Sodium Acetate", synthesized by Sol - Gel Method. Вопросы химии и химической технологии. 2015. Т. 6 (104). С. 80-86.

14. Sukhyy K., Belyanovskaya E., Kovalenko V., Kotok V., Sukhyy M., Kolomiyets E., Gubynskyi M., Yeromin O., Prokopenko O. The study of properties of composite adsorptive materials "silica gel - crystalline hydrate" for heat storage devices. Eastern-European Journal of Enterprise Technologies. 2018. Vol. 91, No. 1. Pp. 52-58. DOI: $10.15587 / 1729-4061.2018 .123896$.

\section{Belyanovskaya E.A., Pustovoy G.N., Sukha I.V., Sklyarenko A.I., Sukhyy M.P., Gubinskyi M.V., Sukhyy K.M. OPERATING PARAMETERS OF ADSORPTIVE CHILLING UNIT OF VAPOR COMPRESSION MACHINE}

Methods for utilization of low-potential thermal energy were studied when vapor compression machine operated. The scheme of a vapor compression refrigerator with an adsorptive chilling unit, which includes a refrigerating chamber, an adsorber, an evaporator and a condenser, has been suggested. As a refrigerant in the adsorptive chilling unit, water is proposed. The procedure for calculation of the operational characteristics of the adsorption chilling unit is proposed. It includes the calculation of value of water mass, adsorbent mass, refrigeration capacity and coefficient of energy performance. The refrigeration capacity and the coefficient of energy performance of the adsorption chilling unit are estimated under conditions of operating a standard compressor refrigeration machine. The main factors affecting the efficiency of the adsorptive chilling unit were analyzed. It has been stated that the refrigeration capacity and coefficient of performance of the adsorptive chilling unit are based on the heat supply to the condenser, and also with a mass of water, which is desorbed and vaporized. The coefficient of performance of the adsorptive chilling unit is estimated to be of 0.878 . The choice criteria for an adsorbent for the adsorptive unit are substantiated to be a temperature of the regeneration, as determined by the temperatures in the condenser, and a maximal adsorption which determined an adsorbent mass. Adequate efficiency of adsorptive chilling units based on silicoaluminophosphates and composite adsorbents "silica gel - sodium acetate" is stated. Perspective of composites "silica gel - $\mathrm{CH}_{3} \mathrm{COONa"} \mathrm{is}$ confirmed. An optimal composition for the composite corresponded with the minimal size for the adsorber is stated to be of $80 \%$ sodium acetate and $20 \%$ for silica gel. The perspectives of the adsorptive conversion of thermal energy for the utilization of low-potential thermal energy during the operation of steam compression refrigeration machines are shown.

Key words: adsorptive conversion of thermal energy, composite adsorbent, vapor compression chilling machine, adsorption, maximal adsorption. 